\title{
T7 polymerase-driven transcription is downregulated in metacyclic promastigotes and amastigotes of Leishmania mexicana
}

\author{
Aygul Ishemgulova ${ }^{1}$, Natalya Kraeva ${ }^{1}$, Drahomíra Faktorová ${ }^{2}$, Lucie Podešvová ${ }^{1}$, Julius Lukeš ${ }^{2,3,4}$ and \\ Vyacheslav Yurchenko ${ }^{1,2,5,6}$
}

${ }^{1}$ Life Science Research Centre, Faculty of Science, University of Ostrava, Ostrava, Czech Republic;
${ }^{2}$ Biology Centre, Institute of Parasitology, Czech Academy of Sciences, České Budějovice, Czech Republic;
${ }^{3}$ Faculty of Sciences, University of South Bohemia, České Budějovice, Czech Republic;
${ }^{4}$ Canadian Institute for Advanced Research, Toronto, Canada;
${ }_{5}^{5}$ Department of Pathology, Albert Einstein College of Medicine, Bronx, NY, USA;
${ }^{6}$ Institute of Environmental Technologies, Faculty of Science, University of Ostrava, Ostrava, Czech Republic.

\begin{abstract}
In our previous work we established a T7 polymerase-driven Tetracycline-inducible protein expression system in Leishmania mexicana (Biagi, 1953). We used this system to analyse gene expression profiles during development of L. mexicana in procyclic and metacyclic promastigotes and amastigotes. The transcription of the gene of interest and the T7 polymerase genes was significantly reduced upon cell differentiation. This regulation is not locus-specific. It depends on untranslated regions flanking open reading frames of the genes analysed. In this paper, we report that the previously established conventional inducible protein expression system may not be suitable for studies on differentiation of species of Leishmania Ross, 1903 and protein expression systems might have certain limitations.
\end{abstract}

Keywords: gene expression, untranslated regions, Tet-inducible system, Leishmania mexicana

Leishmania mexicana (Biagi, 1953) is a flagellated protist of the family Trypanosomatidae causing human cutaneous leishmaniosis, a disease that represents a public health risk in many tropical and subtropical countries (Magill 1995). The genome sequence of this medically important parasite is available (Rogers et al. 2011), but our better understanding of its biology, as well as the evaluation of suitable drug targets still critically depends on functional analysis of proteins of L. mexicana (see Myler 2008). Recently, we have established a T7 polymerase-driven, tetracycline (Tet)-inducible expression system in L. mexicana that was considered suitable for such analyses (Kraeva et al. 2014). Importantly, the application of Tet in trypanosomatid flagellates is not associated with deleterious effects, as is the case in most other eukaryotes (Hashimi et al. 2016).

Leishmania Ross, 1903 and related trypanosomatid parasites utilise an unusual mechanism of gene expression, as a varying number of tandemly arranged genes is transcribed into a single polycistronic precursor (Myler 2008). Subsequently, individual mRNAs are cleaved from this precursor and further processed by trans-splicing at the $5^{\prime}$ end and polyadenylation at the 3' end of each mRNA molecule (Campbell et al. 2003). Due to the polycistronic transcription and the lack of conventional RNA polymerase II promoters, these protists rely on regulating their gene expression post-transcriptionally (Fernandez-Moya and Estevez 2010, Requena 2011). For example, 3' untranslated regions (UTRs) of the protein-coding genes are implicated in regulation at the level of mRNA stability and/or translation (McNicoll et al. 2005, Haile et al. 2008).

Gene expression in dixenous (= two hosts) trypanosomatids must be tightly regulated to allow parasites' fast adaptation to the drastically different environmental conditions they encounter in the vertebrate and invertebrate hosts (Lukeš et al. 2014). The life cycle of Leishmania spp. consists of three main developmental stages: extracellular procyclic and metacyclic promastigotes colonising intestinal tract of the female sandflies of the genera Phlebotomus Loew or Lutzomyia França, and intracellular amastigotes multiplying in the phagolysosomes of mammalian mac-

Address for correspondence: V. Yurchenko, Life Science Research Centre, University of Ostrava, Chittussiho 10 , 71000 Ostrava, Czech Republic. Phone: +420 597092326; Fax: +420 597092382; E-mail: vyacheslav.yurchenko@osu.cz 

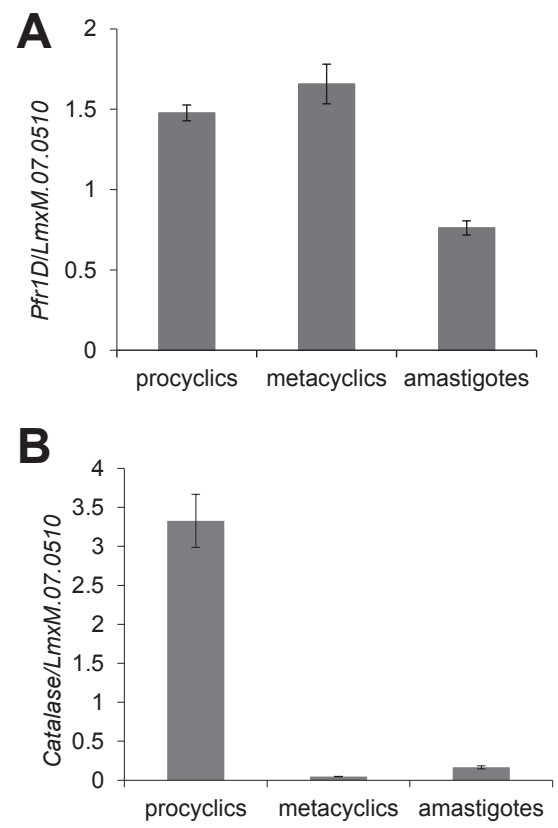
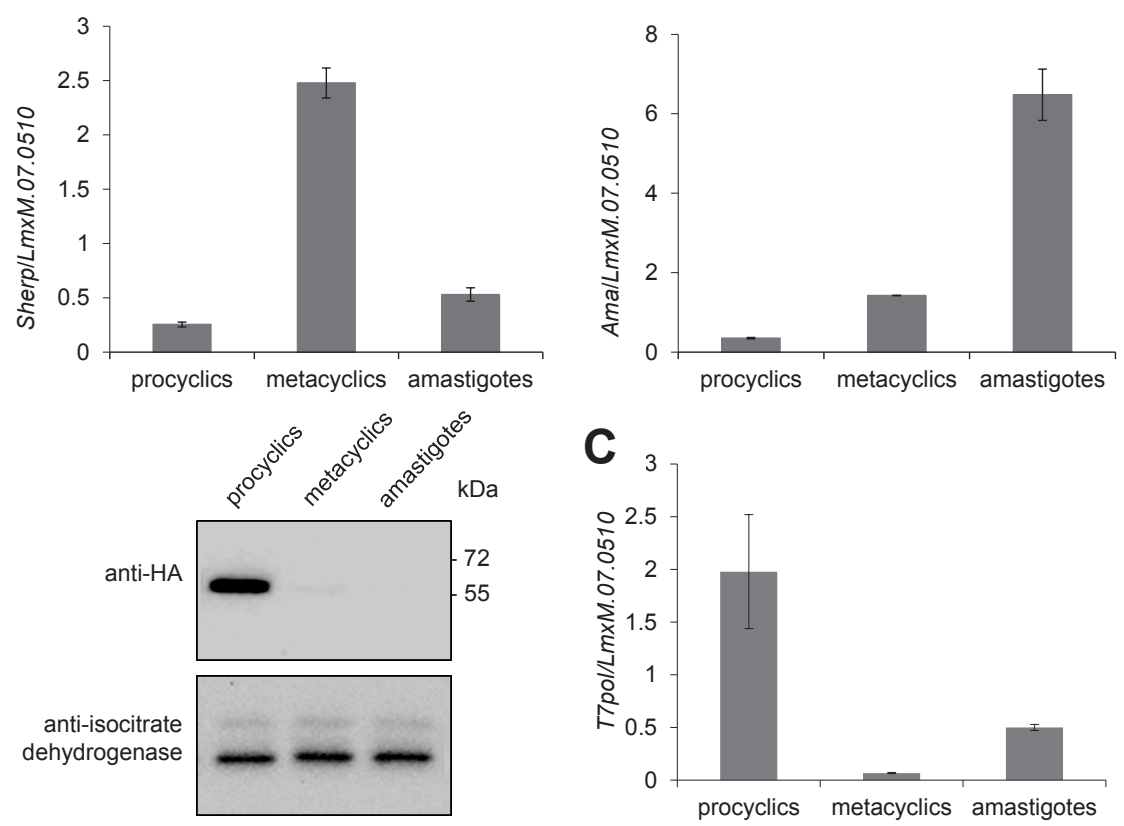

Fig. 1. Heterologous gene expression of the T7TR-HA -catalase in Leishmania mexicana (Biagi, 1953). A - in vitro differentiation of L. mexicana. qPCR quantification of Pfr $1 D$, Sherp and Amastin gene expression used as markers for promastigotes (both pro- and metacyclics), metacyclics, and amastigotes, respectively; B - qPCR quantification and Western blot analysis of the HA $\mathrm{H}_{3}$-catalase expression in the differentiated cells after induction with $10 \mu \mathrm{g} / \mathrm{ml}$ of Tetracycline for 24 hours. Whole cell extracts were probed with $\alpha$-HA and $\alpha$-isocitrate dehydrogenase antibodies with the latter as a loading control; $\mathbf{C}-$ qPCR quantification of the T7 RNA polymerase expression analysed as above. Data for three independent biological replicates normalised to the LmxM.07.0510 are shown in all cases. Detailed protocols were described previously (Kraeva et al. 2014, Záhonová et al. 2014). Primer sequences used for qPCR are available from authors upon request.

rophages (Bates 1994a). Metacyclics and amastigotes are pathogenic and thus can be used for identification of virulence factors of species of Leishmania in vitro and in vivo.

In this work we used the established transgenic L. mexicana T7TR system and followed the fate of the overexpressed protein during differentiation of parasites in vitro (Kraeva et al. 2014). The gene of interest was a catalase which is conspicuously absent from all species of Leishmania investigated thus far. This is one of the most potent enzymes on the Earth with Kcat reaching $10^{7}$ molecules of $\mathrm{H}_{2} \mathrm{O}_{2}$ per second. Its presence in all monoxenous relatives of Leishmania (species of Leptomonas Kent, 1880, Crithidia Léger, 1902 and Lotmaria Evans et Schwarz, 2014 of the subfamily Leishmaniinae - see Jirků et al. 2012) requires further investigation (Kraeva et al. 2015, Flegontov et al. 2016). The entire open reading frame of the catalase gene, PCR-amplified from DNA of the H10 isolate of Leptomonas pyrrhocoris Zotta, 1912 (Votýpka et al. 2012), was integrated into the $\beta$-tubulin locus and expressed in a T7 polymerase-dependent, Tet-inducible way.

Parasites were differentiated in vitro by changing the temperature and $\mathrm{pH}$ of the media (Bates 1994b). Proper separation of developmental stages of $L$. mexicana was confirmed by expression analysis of selected stage-regulated genes using qPCR as described earlier (Záhonová et al. 2014). The genes encoding PFR1D (LmxM.08_29.1750, LmxM.08_29.1760), SHERP (LmxM.23.1050, LmxM.23.1061) and Amastin (LmxM.08.0800, LmxM.08.0840, LmxM.08.0850) were used as promastigotes- (procyclics and metacyclics), metacyclics- and amas- tigotes-specific gene markers, respectively (Rochette et al. 2008, Sádlová et al. 2010) (Fig. 1A). A homolog of the 60S ribosomal protein L7a (LmxM.07.0510) was chosen as a reference based on our whole-transcriptome analysis of developmental stages of $L$. mexicana (Flegontov et al. 2016).

Other genes with similar expression patterns - ubiquitin hydrolase (UbH, LmxM.08_29.2300), short chain 3-hydroxyacyl-CoA dehydrogenase (LmxM.36.1140), serine acetyltransferase (LmxM.33.2850), and 60S ribosomal protein L17 (LmxM.24.0040) - were analysed in parallel. Normalisation to these genes did not significantly change the results (data not shown). The expression of catalase of L. pyrrhocoris in differentiated stages was analysed by qPCR and Western blotting. Both, the mRNA and protein levels were strikingly decreased in metacyclics and amastigotes (Fig. 1B). Comparison of the catalase and the T7 polymerase expression profiles at different developmental stages revealed a similar pattern (Fig. 1C). This is not surprising, provided that the transcription of catalase is T7 polymerase-driven.

To verify that the decrease of gene expression in metacyclics and amastigotes is not sequence-specific, we replaced the T7 polymerase open reading frame by that of mCherry as described previously (Kraeva et al. 2015). The construct was integrated into the same $18 S$ rRNA locus (Kushnir et al. 2005) and expression of the mCherry protein was confirmed by fluorescence microscopy (data not shown). The differentiation of the transgenic culture and proper separation of the life cycle stages were verified by 

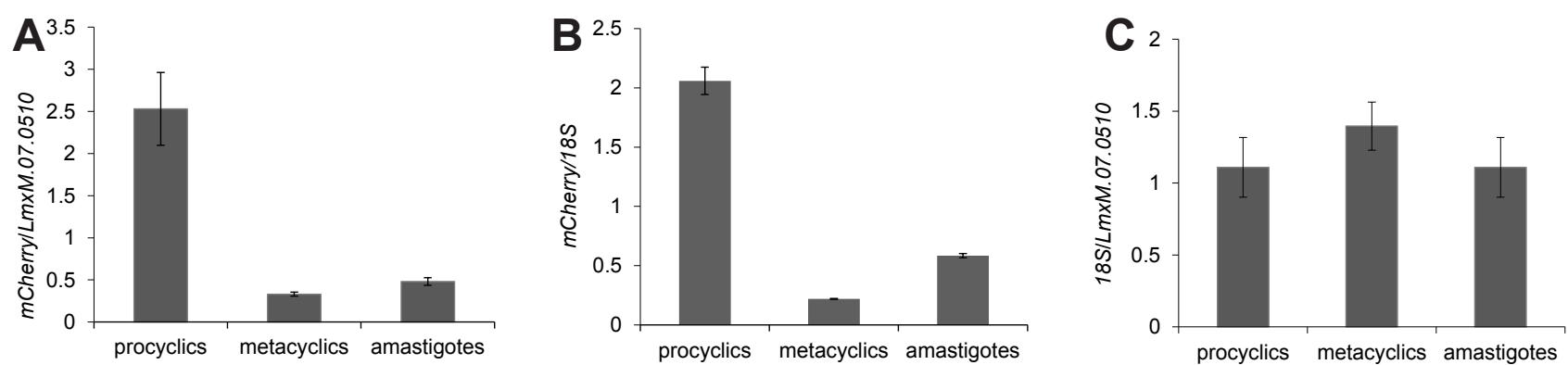

Fig. 2. A,B - mCherry gene expression in Leishmania mexicana (Biagi, 1953). mRNA expression level of mCherry in differentiated procyclics, metacyclics, and amastigotes. LmxM.07.0510 and $18 S$ rRNA genes were used for normalisation in A and B, respectively; C- expression of the $18 S \mathrm{rRNA}$ is stable throughout development of L. mexicana. Results of three independent biological replicates are presented. Detailed protocols were described previously (Kraeva et al. 2014, Záhonová et al. 2014). Primer sequences used for qPCR are available from authors upon request.

qPCR as described above. Next, we examined the expression profile of the mCherry transcript in differentiated procyclics, metacyclics and amastigotes and confirmed it to be similar to that of the catalase and T7 polymerase (Fig. 2A).

The mCherry, T7 polymerase and Tet-repressor genes were all integrated into the $18 \mathrm{~S}$ rRNA locus. Previous studies showed a 5 to 20 -fold decrease in transcription of several RNAs derived from this locus during Leishmania donovani (Laveran et Mesnil, 1903) differentiation (Saxena et al. 2007). To exclude an influence of the rRNA locus-dependent regulation on the reporter genes expression, we compared mCherry expression profile normalised to the $18 S$ and $L m x M .07 .0510$ genes (Fig. 2A,B). Similar patterns of the mCherry mRNA expression suggest that gene expression regulation in our system is not locus-specific. As a control, we analysed expression of the 18S rRNA and confirmed it to be stable throughout development (Fig.2C).

Although the molecular mechanisms governing expression of developmental genes during the promastigote-to-amastigote differentiation are not well understood and characterised, a number of reports have demonstrated that protein abundance is chiefly controlled by mRNA stability. It depends on the sequences present in both $5^{\prime}$ and $3^{\prime}$ UTRs (Aly et al. 1994, Charest et al. 1996, Garcia-Estrada et al. 2008).

In our study, the mCherry, $\mathrm{T} 7$ polymerase, and Tet-repressor genes were flanked by the UTRs derived from the calmodulin (LtaP.09.0940) intergenic regions of Leishmania tarentolae Wenyon, 1921 (Breitling et al. 2002, Kush- nir et al. 2005). Whole-transcriptome profiling revealed that calmodulin mRNA abundance in species of Leishmania is developmentally regulated. It is reduced by $1.5-2$ fold upon differentiation from procyclics to metacyclics and amastigotes (Aslett et al. 2010, Dillon et al. 2015). Patterns of the expression of reporter genes upon differentiation of L. mexicana followed those of calmodulin. The discrepancy in the degree of downregulation can be explained by differences in calmodulin expression regulation in L. tarentolae and L. mexicana.

In summary, here we would like to draw attention of the parasitology community to the potential limitations that conventional gene expression systems might have in the studies of the development of species of Leishmania.

Acknowledgements. We would like to thank members of our laboratories for helpful discussions and technical assistance. Special thanks are due to Alena Krejčí and Eva Horáková (Biology Centre, České Budějovice) for providing us with Living Colors DsRed and anti-isocitrate dehydrogenase antibodies. The mCherry expressing plasmid was a gift from Mark Carrington (University of Cambridge). This work was supported by the Czech Science Foundation (grants 13-24983S to VY and 16-18699S to JL and VY), AI was supported by the grant 0924/2016/ŠSaS from the Statutory City of Ostrava, the Moravskoslezský Kraj research initiative (grants DT1/RRC/2013-2014 and 00955/RRC/2015 to $\mathrm{VY}$ ) and by the grant SGS/PrF/2016 from the University of Ostrava (to AI, NK and LP). The financial support through the project LO1208 ('TEWEP') of the National Feasibility Programme I of the Ministry of Education, Youth and Sports of the Czech Republic is gratefully appreciated.

\section{REFERENCES}

Aly R., Argaman M., Halman S., Shapira M. 1994: A regulatory role for the 5' and 3' untranslated regions in differential expression of hsp83 in Leishmania. Nucl. Acids Res. 22: 2922 2929.

Aslett M., Aurrecoechea C., Berriman M., Brestelli J., Brunk B.P., Carrington M., Depledge D.P., Fischer S., Gajria B., Gao X., Gardner M.J., Gingle A., Grant G., Harb O.S., Heiges M., Hertz-Fowler C., Houston R., Innamorato F., Iodice J., Kissinger J.C., Kraemer E., Li W., Logan F.J., Miller J.A., Mitra S., Myler P.J., Nayak V., Pennington C., Phan I., Pinney D.F., Ramasamy G., Rogers M.B., Roos D.S., Ross C., Sivam D., Smith D.F.,
Srinivasamoorthy G., Stoeckert C.J., Jr., Subramanian S., Thibodeau R., Tivey A., Treatman C., Velarde G., WANG H. 2010: TriTrypDB: a functional genomic resource for the Trypanosomatidae. Nucl. Acids Res. 38: D457-462.

Bates P.A. 1994a: The developmental biology of Leishmania promastigotes. Exp. Parasitol. 79: 215-218.

Bates P.A. 1994b: Complete developmental cycle of Leishmania mexicana in axenic culture. Parasitology 108: 1-9.

Breitling R., Klingner S., Callewaert N., Pietrucha R., Geyer A., Ehrlich G., Hartung R., Muller A., Contreras R., Beverley S.M., Alexandrov K. 2002: Non-patho- 
genic trypanosomatid protozoa as a platform for protein research and production. Protein Expr. Purif. 25: 209-218.

Campbell D.A., Thomas S., Sturm N.R. 2003: Transcription in kinetoplastid protozoa: why be normal? Microbes Infect. 5: 1231-1240.

Charest H., Zhang W.W., Matlashewski G. 1996: The developmental expression of Leishmania donovani A2 amastigote-specific genes is post-transcriptionally mediated and involves elements located in the 3'-untranslated region. J. Biol. Chem. 271: 17081-17090.

Dillon L.A., Okrah K., Hughitt V.K., Suresh R., Li Y., Fernandes M.C., Belew A.T., Corrada Bravo H., Mosser D.M., El-SAYed N.M. 2015: Transcriptomic profiling of gene expression and RNA processing during Leishmania major differentiation. Nucl. Acids Res. 43: 6799-6813.

Fernandez-Moya S.M., Estevez A.M. 2010: Posttranscriptional control and the role of RNA-binding proteins in gene regulation in trypanosomatid protozoan parasites. Wiley Interdiscip Rev RNA 1: 34-46.

Flegontov P., Butenko A., Firsov S., Kraeva N., Eliáš M., Field M.C., Filatov D., Flegontova O., Gerasimov E.S., Hlaváčová J., Ishemgulova A., Jackson A.P., Kelly S., Kostygov A., Logacheva M.D., Maslov D.A., Opperdoes F.R., O’Reilly A., SÁdlová J., Ševčíková T., Venkatesh D., VlČeK Č., Volf P., VotÝPKa J., ZÁhonová K., YurChENKO V., LuKEŠ J. 2016: Genome of Leptomonas pyrrhocoris: a high-quality reference for monoxenous trypanosomatids and new insights into evolution of Leishmania. Sci. Rep. 6: 23704.

Garcia-Estrada C., Perez-Pertejo Y., Ordonez D., BalaNA-Fouce R., Reguera R.M. 2008: Characterization of the 5' region of the Leishmania infantum LORIEN/MAT2 gene cluster and role of LORIEN flanking regions in post-transcriptional regulation. Biochimie 90: 1325-1336.

Haile S., Dupe A., Papadopoulou B. 2008: Deadenylation-independent stage-specific mRNA degradation in Leishmania. Nucl. Acids Res. 36: 1634-1644

Hashimi H., Kaltenbrunner S., Zíková A., Lukeš J. 2016 Trypanosome mitochondrial translation and tetracycline: no sweat about Tet. PLoS Pathog. 12: e1005492.

JirkŮ M., Yurchenko V.Y., Lukeš J., Maslov D.A. 2012: New species of insect trypanosomatids from Costa Rica and the proposal for a new subfamily within the Trypanosomatidae. J. Eukaryot. Microbiol. 59: 537-547.

Kraeva N., Butenko A., Hlaváčová J., Kostygov A., MyšKova J., Grybchuk D., Leštinová T., VotýpKa J., Volf P., Opperdoes F., Flegontov P., Lukeš J., Yurchenko V. 2015: Leptomonas seymouri: adaptations to the dixenous life cycle analyzed by genome sequencing, transcriptome profiling and co-infection with Leishmania donovani. PLoS Pathog. 11: e1005127.

Kraeva N., Ishemgulova A., Lukeš J., Yurchenko V. 2014 Tetracycline-inducible gene expression system in Leishmania mexicana. Mol. Biochem. Parasitol. 198: 11-13.
Kushnir S., Gase K., Breitling R., Alexandrov K. 2005: Development of an inducible protein expression system based on the protozoan host Leishmania tarentolae. Protein Expres. Purif. 42: $37-46$.

Lukeš J., SkalickÝ T., TÝČ J., VotÝpka J., Yurchenko V. 2014: Evolution of parasitism in kinetoplastid flagellates. Mol. Biochem. Parasitol. 195: 115-122.

Magill A.J. 1995: Epidemiology of the leishmaniases. Dermatol. Clin. 13: 505-523.

McNicoll F., Muller M., Cloutier S., Boilard N., RoChette A., Dube M., Papadopoulou B. 2005: Distinct 3'-untranslated region elements regulate stage-specific mRNA accumulation and translation in Leishmania. J. Biol. Chem. 280: 35238-35246.

Myler P.J. 2008: Genome structure and content. In: P.J. Myler and N. Fasel (Eds.), Leishmania: After the Genome. Caister Academic Press, Wymondham, pp. 15-28

REQUENA J.M. 2011: Lights and shadows on gene organization and regulation of gene expression in Leishmania. Front. Biosci. 17: 2069-2085.

Rochette A., Raymond F., Ubeda J.M., Smith M., Messier N., Boisvert S., Rigault P., Corbeil J., Ouellette M., PaPADOPOULOU B. 2008: Genome-wide gene expression profiling analysis of Leishmania major and Leishmania infantum developmental stages reveals substantial differences between the two species. BMC Genomics 9: 255.

Rogers M.B., Hilley J.D., Dickens N.J., Wilkes J., Bates P.A., Depledge D.P., Harris D., Her Y., Herzyk P., Imamura H., Otto T.D., Sanders M., Seeger K., Dujardin J.C., Berriman M., Smith D.F., Hertz-Fowler C., MotTRAM J.C. 2011: Chromosome and gene copy number variation allow major structural change between species and strains of Leishmania. Genome Res. 21: 2129-2142.

SÁdlová J., Price H.P., Smith B.A., VotÝPKa J., Volf P., Sмiтн D.F. 2010: The stage-regulated HASPB and SHERP proteins are essential for differentiation of the protozoan parasite Leishmania major in its sand fly vector, Phlebotomus papatasi. Cell Microbiol. 12: 1765-1779.

Saxena A., Lahav T., Holland N., Aggarwal G., Anupama A., Huang Y., Volpin H., Myler P.J., Zilberstein D. 2007: Analysis of the Leishmania donovani transcriptome reveals an ordered progression of transient and permanent changes in gene expression during differentiation. Mol. Biochem. Parasitol. 152: $53-65$.

Votýpka J., Klepetková H., Yurchenko V.Y., Horák A., Lukeš J., Maslov D.A. 2012: Cosmopolitan distribution of a trypanosomatid Leptomonas pyrrhocoris. Protist 163: 616-631.

Záhonová K., Hadariová L., Vacula R., Yurchenko V., Eliáš M., KrajČoviČ J., Vesteg M. 2014: A small portion of plastid transcripts is polyadenylated in the flagellate Euglena gracilis. FEBS Lett. 588: 783-788.

Cite this article as: Ishemgulova A., Kraeva N., Faktorová D., Podešvová L., Lukeš J., Yurchenko V. 2016: T7 polymerase-driven transcription is downregulated in metacyclic promastigote and amastigote Leishmania mexicana. Folia Parasitol. $63: 016$. 